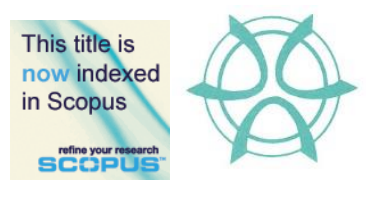

PLANNING MALAYSIA:

Journal of the Malaysian Institute of Planners

VOLUME 17 ISSUE 1 (2019), Page 338 - 349

\title{
3D CITY MODELING USING MULTIROTOR DRONE FOR CITY HERITAGE CONSERVATION
}

\author{
Norzailawati Mohd Noor ${ }^{1}$, Ahmad Afiq Aiman Abdullah², Alias Abdullah ${ }^{3}$, \\ Illyani Ibrahim ${ }^{4} \&$ Saadman Sabeek ${ }^{5}$ \\ ${ }_{1,2,3,4,5}$ Kulliyyah of Architecture and Environmental Design \\ INTERNATIONAL ISLAMIC UNIVERSITY MALAYSIA
}

\begin{abstract}
This paper aims to construct a 3D Malay city based on data collected from DJI Phantom 3, a multi rotor drone, and further analyse the urban form of traditional Malay cities using 3 main urban form components which are buildings, land use and streets. Kota Bharu was selected as the study area and the flight mission produced 793 images which were processed in Agisoft and further constructed 3D GIS in ArcGIS 10.2. The analysis of urban form shows that the old traditional development in north-north west still maintain the identity of Malay urban form, of the organic pattern of streets, preserve Malay architectures and the type of land use for traditional settlement. This finding shows that, Malay values in cities and architecture still remain and it must be preserved from any development and it can be a benchmark on adapting technologies and shifting methods in conservation and safeguarding our heritage cities in Malaysia.
\end{abstract}

Keyword: Multirotor Drone, 3D modelling, Mapping, Malay urban form and urban planning 
PLANNING MALAYSIA

Journal of the Malaysia Institute of Planners (2019)

\section{INTRODUCTION}

Drone technology or unmanned aerial vehicle (UAV), nowadays, keeps on developing and spreading, in line with the needs of the technology in daily life. The research and invention of the technology keep on growing and rapidly evolves. Two types of UAV systems are fixed wing and rotary. Rotary has almost the same design concepts with a helicopter except it was designed with single or multirotor. A rotary UAV system with a single rotor has the same structure with a manned helicopter, while a multirotor has more than one motor (Lin et al., 2011; Zhang et al., 2012). There are many models of drones and UAVs in the market, varies from multirotor types and fixed wings types carrying different functions and purposes (Hassanalian, 2017). Drones nowadays can be recognized as a tool for data collection related with aerial images. The conventional method of using a helicopter or an aeroplane involves large amounts of money compared to drone technologies which are cheaper. The usage of drone technologies in urban planning becomes more important in helping decision making, especially in the data collection process that relates to physical development.

Three-dimensional (3D) city models represent and animate all urban features including buildings, streets, open spaces on a computer platform. A 3D model shows what is going to change and happen at the end of a new design. It explains the results of recommended changes visually. To reach a beneficial decision, it convinces decision makers by providing sufficient argument in simulating real world and reconstructing a planned project to predict a possible result. 3D models make processing the real world easy and there are many applications for 3D modelling in urban planning especially when dealing with contemporary urban issues. The data generation process is conventionally manual and all of them comprise the whole historical, archeological and constructive information required to understand the heritage structure and its evolution over time (Messoudi et al., 2018). The creation of 3D models of heritage cities and sites in their current state requires a powerful methodology that is able to capture and digitally model the fine geometric and appearance details of such sites. Digital recording, documentation and preservation are demanded as our heritages (natural, cultural or mixed) suffer from on-going attrition, wars, natural disasters, climate change and human negligence. In particular, the built environment and natural heritage have received a lot of attention and benefit from the recent advancement of range sensors and imaging devices (Clarke, 2014; Li et al., 2008; $\mathrm{Li}$ et al., 2009). Nowadays, 3D data is a critical component to permanently record the form of important objects and sites, so that, in digital form at least, they might be passed down to future generations. Although digitally recorded and modeled, our heritage requires more international collaboration and information sharing to make them accessible in all possible forms and to all possible users and clients.

Recently, drones or Unmanned Aerial Vehicles (UAV) were used to obtain 3D mapping and models. This inexpensive equipment is capable in making 
Norzailawati Mohd Noor, Ahmad Afiq Aiman Abdullah, Alias Abdullah, Illyani Ibrahim \& Saadman Sabeek $3 D$ City Modeling Using Multirotor Drone for City Heritage Conservation

sophisticated maps. Small and portable drones are quickly deployable. They carry lightweight digital cameras that can capture good quality images. The capabilities of drone applications have been tested in many projects (Greenwood, 2015). Using drones, 3D models can be generated from either nadir imagery (shot vertically straight down) or oblique imagery (from an angle to the side), but the most detailed model combines both into a single representation. To generate a 3D model, a software requires hundreds of overlapping still images. The arrangement of flight planning consists of its flight route, percentage of overlapping, number of images, sensors, altitude and geo-referencing (Greenwood, 2015). Pix4D and Agisoft PhotoScan are the two most well-known paid aerial imagery and photogrammetry processing choices with relatively simple user interfaces and comprehensible manuals, as well as an established track record of use for professional aerial mapping applications. Both programs are regularly updated and improved upon, as the demand for UAV mapping and the market for photogrammetry software expands. The consideration of these aspects will make this flight different from other usage of drones.

In the context of Malay urban form, it is stated that the formation of its city was based on the ruling systems where the King is the state ruler and has very powerful influence in decision making and also the factor of natural elements as well as geographical conditions (Harun \& Jalil, 2014). The urban morphology and figure-ground of estuary towns in the Malay states have almost identical characteristics. Palaces as centres of governance were built overlooking wide open spaces or squares. Located close to the palaces were mosques, buildings for ministerial use, buildings for the ruling institution (government buildings) such as court houses and district offices, market and commercial stores and public dwellings. The royal institution may be seen as an agent of urban morphology and this was proven with the construction of buildings and settlements around the palace grounds as well as from other urban elements that were planned and laid out in such meaningful patterns. Therefore, this study attempts to construct a 3D Malay city based on data collected from the multi rotor drone DJI Phantom 3 and further analysis of the urban form for traditional Malay cities using 3 main components, which are buildings, land use and streets. Kota Bharu has been selected as the study area and this study expects to be a benchmark of shifting to technologies in conserving and safeguarding our heritage cities in Malaysia specifically.

\section{Study Area}

Kota Bharu, significantly means "New Fort" which resembles the establishment of the new city in 1845 (Fig. 1). Traditional Malay cities use fort boundaries to resemble their main city boundaries which contained the administrative centre for the city. Istana Balai Besar was the royal symbol for Kelantanese and it was one of the early palaces of Sultan Kelantan which was built during the $18^{\text {th }}$ century. 
PLANNING MALAYSIA

Journal of the Malaysia Institute of Planners (2019)

Sultan Muhammad II built Istana Balai Besar as a new palace and as the administrative centre in Kota Bharu. From that point, the development of Kota Bharu was planned by a local planner and architect. During that time, Kota Bharu grew as an established city until the British came to Kelantan during the $19^{\text {th }}$ century. The location of Istana Balai Besar was near the river and surrounded by existing communal areas are factors for the site selection of the construction of the new palace.

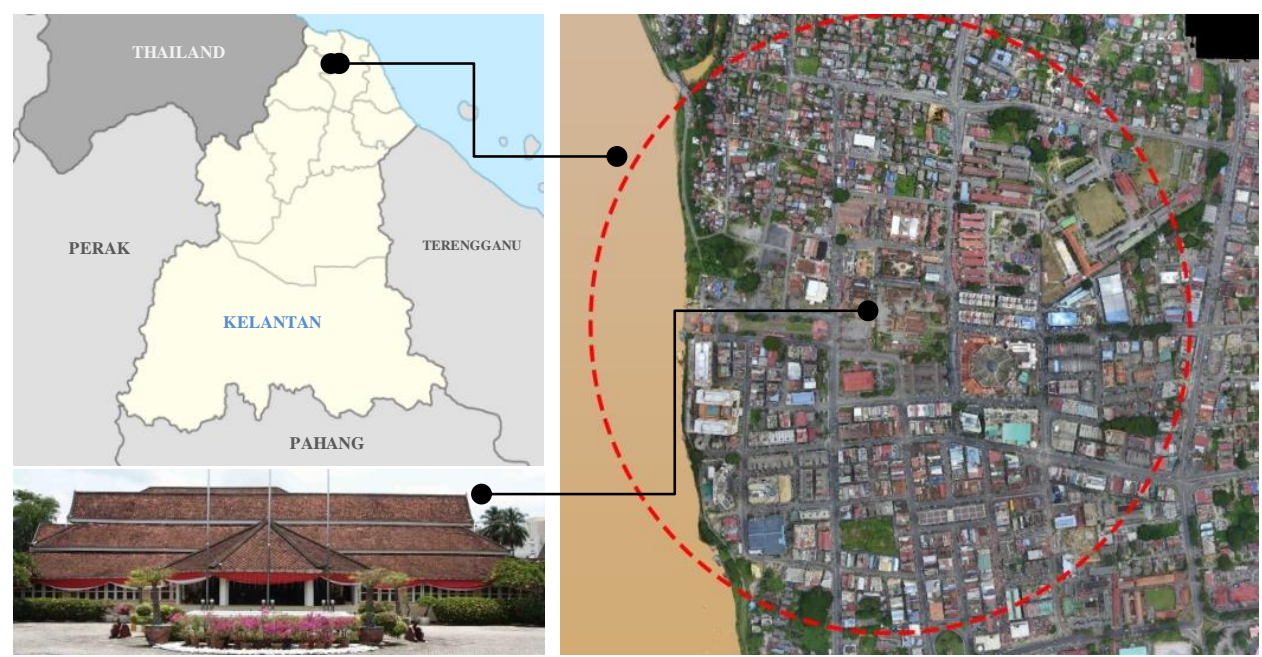

Figure 1: The location of the study area with identified 500-meter radius from the main palace

\section{MATERIAL AND METHOD}

\section{Material and software}

There are two types of data that were used in this paper which are primary data and secondary data. Primary data represents data collected using the multirotor drone, while secondary data consists of old maps, land use maps, GIS data from the local authority and also the historical data of Kota Bharu. All the data are categorized under materials needed to produce the 3D GIS model. Several software were used as tools for data sorting, data processing, 3D model constructing and for analysing the results. The multirotor drone was used as the tool for capturing aerial images data. There are a few factors for the drone type selection, such as cost involved, coverage of the area, and also the compatibility of software to run the research. The DJI Phantom 3 drone was selected for the data capturing processes. Table 1 describes the specification of this equipment. 
Norzailawati Mohd Noor, Ahmad Afiq Aiman Abdullah, Alias Abdullah, Illyani Ibrahim \& Saadman Sabeek $3 D$ City Modeling Using Multirotor Drone for City Heritage Conservation

Table 1: Specification of Multi Rotor UAV used in this study

\begin{tabular}{|l|l|}
\hline Specification & Description \\
\hline UAV System & Multi rotor (4 rotors) \\
\hline Model & DJI Phantom 3 Standard \\
\hline Battery Weight & 365 grams \\
\hline Flight time & 25 minutes \\
\hline
\end{tabular}

For flight planning, we used Pix4dcapture in setting up the waypoints for our flight mission. The Agisoft software was used when processing drone images. GIS software such as MapInfo and ArcGIS (City Engine) were used in finalizing the urban form analysis.

\section{Methodology}

The methodology can be divided into four main processes which consists of flight preparation, data pre-processing, 3D GIS model and urban form analysis. The process flow can be seen in figure 2 as shown below.

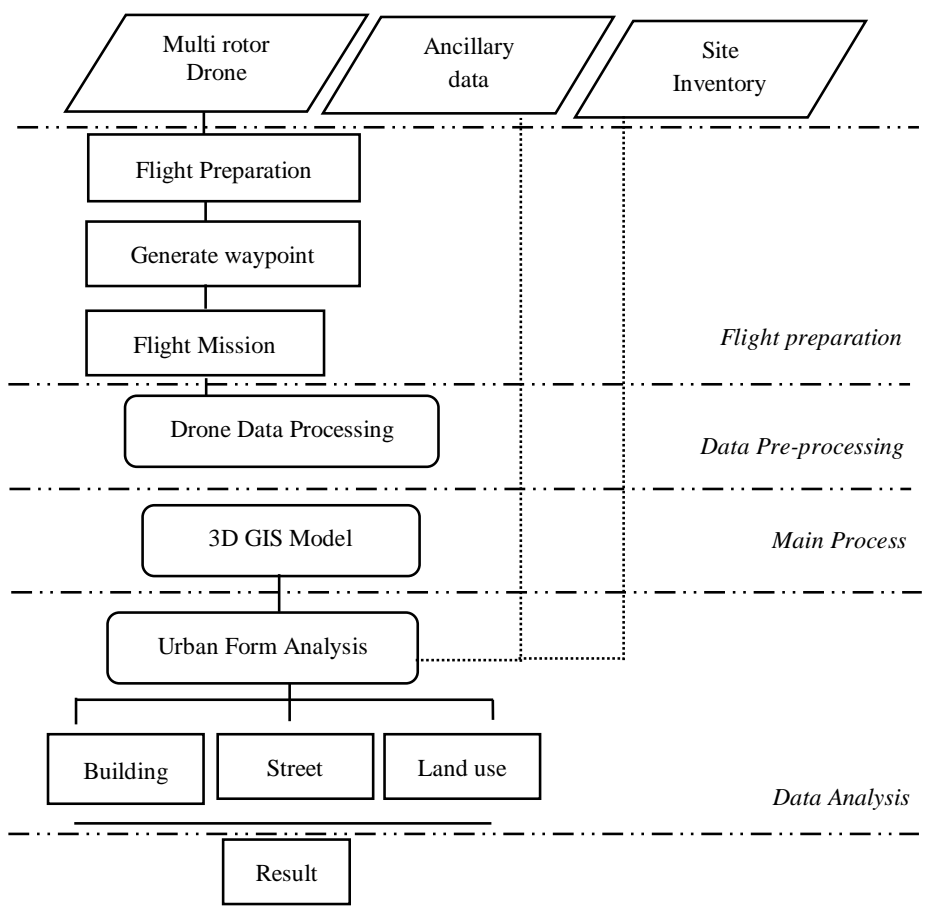

Figure 2: Flowchart of study methodology

There are four main phases of methodology conducted in this study which are flight preparation, data pre-processing, main process and data analysis. 
PLANNING MALAYSIA

Journal of the Malaysia Institute of Planners (2019)

\section{Flight Preparation}

This stage discusses flight planning or flight preparation. There are a few important elements to be syhnronized to ensure the quality and make the imageries suit our objective. The elements consist of the route, image overlapped, altitude, sensor and georeferencing. Aerial image acquisition of this drone was conducted on $23^{\text {rd }}$ September 2017. Drone mapping missions are designed to ensure each image adequately overlaps with subsequent images, making it possible for processing software to merge the image. To achieve a certain image overlap, we need to balance the speed of flight with the interval at which the camera is taking pictures, the altitude of the flight, the distance between the transects, and the internal geometry of the camera. The double grid mode sets $2 \mathrm{x}$ standard 2D grid paths@90\% to each other, with a camera angle of $45^{\circ}$ to pick up data from a vertical façade. The altitude of the drone was set to 150 meters to avoid tall buildings and only a portion of the area was set to an altitude of 200 meters to avoid losing signal because of telecommunication towers in the area. The minimum overlap setting was frontal $80 \%$ and side $65 \%$.

Three ground stations were set up in the site to launch the drone. We captured 793 images, and each of them contained parameters such as projection file, WGS 84 coordinate data and Z-axis data, and these information is useful for constructing the 3D model of the city. Using PIX4dcapture, the flight path was set up to fly in a rectangular path rather than a circular path because a circular flight path is most suitable for single building data collection.

\section{Data Pre-processing}

Data pre-processing represents the stage where we obtained 3D models from the drone imageries. Raw drone images were downloaded into a computer after a flight mission is completed. Each image was saved in a JPEG file format and the quality of images were checked. Image errors such as blur and color balancing are some of the quality problems due to altitude differences during the flight mission. To generate a 3D map, the Agisoft software requires hundreds of overlapping still images. This software can automatically construct a 3D model for Kota Bharu without setting initial values and control points and it is a convenient process for this stage. It automatically aligns with the camera once all images are loaded into the software after distortion treatment. Technically, the software will search for the corresponding points and match images and the same time identified the location it have been captured. Once the photo alignment is complete, the software generates a sparse point cloud with a set of associated camera positions and internal camera parameters. A sparse cloud is adequate to produce a less detailed 3D model that doesn 't need to be precisely geo-referenced. Next, the software builds a 3D polygonal "mesh" based on the dense point cloud representing the surface of the object, like a net thrown over a three-dimensional object. For the final step, the software lays textures taken from the original 
Norzailawati Mohd Noor, Ahmad Afiq Aiman Abdullah, Alias Abdullah, Illyani Ibrahim \& Saadman Sabeek $3 D$ City Modeling Using Multirotor Drone for City Heritage Conservation

photograph over the 3D mesh, giving the original flat imagery a sense of depth and volume for the final 3D model that can be used for this study.

\section{D GIS Modeling}

The image was processed using ArcGIS 17 for the final output. We need to specify a certain parameter to ensure the quality of the result. The parameters, such as key points, are point generated during image processing and represent a unique location in an image. Thousands of key points are generated for each image in this study. Keypoints that represent the same area in different images, known as tie points, are matched to determine where images overlap. The next parameter is Matching Image Pairs, which determines which kinds of image pairs are matched with the key points. The Aerial grid technique was used to organize an image along a grid or corridor (straight line) flight path including point cloud densification was carried out in next stage and further with textured meshed. The 3D mesh contains an accurate representation of the building as shown in the original drone imagery.

\section{Urban Form Analysis}

The analysis of urban form is to investigate the heritage trail in Kota Bharu city according to land use, streets and buildings that remain on the site. The physical form based on visualization and GIS databases of this urban form were analysed from the 3D model from the previous stage. The overlay process to carry out the structures of urban form have been conducted and compared with the existing data. The next processes further are the specific analysis on street size/hierarchy, pattern, building in height and building pattern.

\section{RESULT AND DISCUSSION}

By using Agisoft, construction of 3D GIS models were automatically done based on data captured using the drone. It means that during the data capture, the data must be accurate with minimal error and to be sure that the GPS data for each image taken was stored. The GPS data is important to align the images accordingly and ensure that there are no wrong images which are redundant that can result in an inaccurate 3D GIS model. Principally, the more images overlapped the more accurate the data.

All the overlapping images will be merged to produce a single aerial image that covers the whole area. As resulted from the rectangular shape flight path, the Z-axis data was captured and the 3D GIS model was automatically constructed based on the point cloud created after the image allignment process. Figure 3 shows overall 3D GIS models that were constructed in Agisoft software. Besides from exporting the $3 \mathrm{D}$ model as images, point cloud is also one of the options provided by Agisoft. Point cloud data can be used for further GIS analysis 
PLANNING MALAYSIA

Journal of the Malaysia Institute of Planners (2019)

in Argis software. For the study, the analysis was more focused on the Malay urban pattern analysis that will be extracted from the 3D GIS model.

\section{D City Modelling}

The construction of the 3D model was carried out using Agisoft PhotoScan. Figure 3 shows the 3D Ortho model of the area covered with the images representing the types of buildings in 3D. The study area are successfully covered during the data collection process and the overlapping between the images captured was set up to $80 \%$, the accuracy of the data collection was quite high and acceptable for the construction of 3D GIS model and aerial mapping.

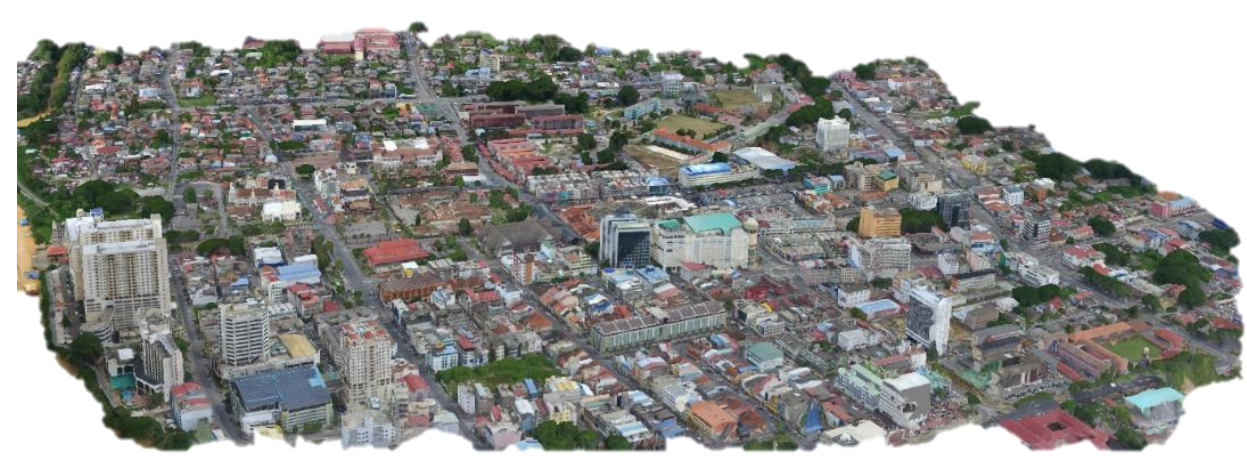

Figure 3: 3D Ortho model reconstruction for Malay city

\section{Malay Urban Form for Kota Bharu}

\section{Street Pattern}

The street pattern analysis shows there are two different street patterns found at the existing site. Based on the site inventories that has been conducted in this study (Fig. 4), the two different street patterns for the study area representing the old traditional village or settlement in north-north west that already existed for the last few hundred years, while in another section of the study area was influenced by colonials especially after the British setting ups their administration in Kota Bharu. We can identify the difference that existed as an organic pattern street in the traditional settlement and more towards grid street pattern in the other areas. 
Norzailawati Mohd Noor, Ahmad Afiq Aiman Abdullah, Alias Abdullah, Illyani Ibrahim \& Saadman Sabeek $3 D$ City Modeling Using Multirotor Drone for City Heritage Conservation

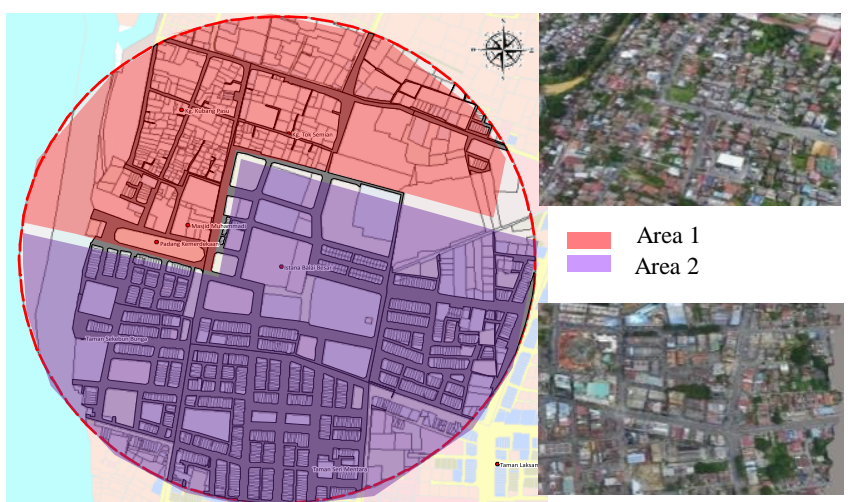

Figure 4: Malay street pattern analysis that influences the urban form at the area 1 and area 2

\section{Building Pattern Analysis}

According to the division of the development era, the analysis of building patterns in the study area was carried out. Figure 5 shows that most of the building types were housing and there are some of the houses that still preserve and maintain Malay traditional architecture elements which are significant with the identity of traditional Kelantanese architecture, while area 2 shows building patterns following British architecture style.
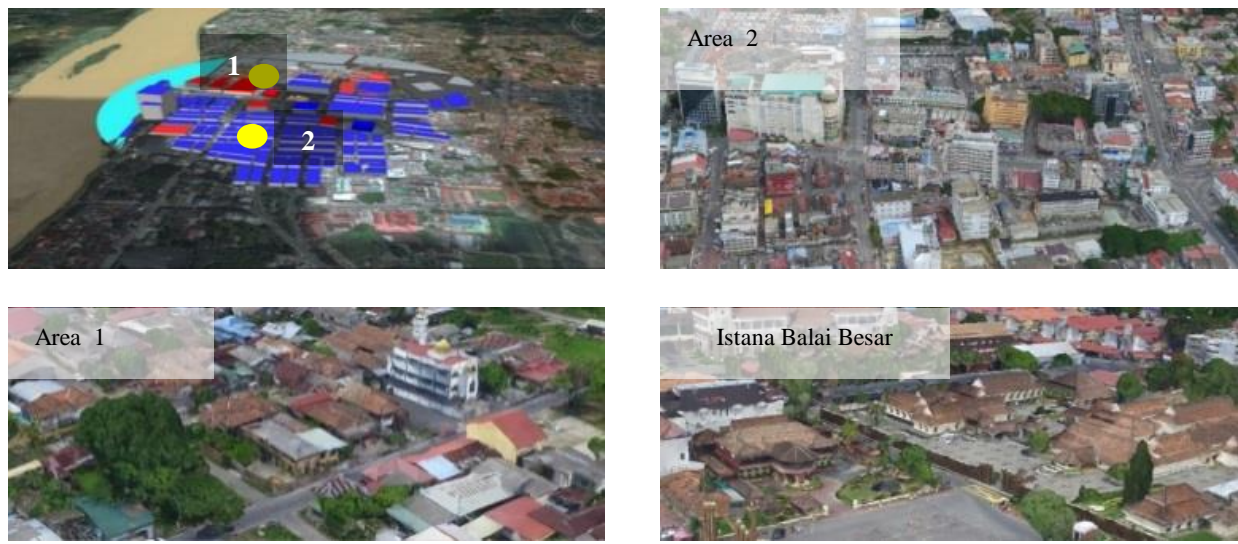

Figure 5: Showing varieties of building types in area 1: traditional Malay houses, area 2: British architecture in commercial areas and Istana Balai Besar that still keep Malay architecture

\section{Land use Analysis Pattern}

Land use pattern analysis shows that major land use for the study area consists of two major categories which are commercial and residential. Historically, there are evidences that show that the location of Istana Balai Besar (palace) and a few 
other traditional buildings that exist since 1845 was considered as the administrative centre of Kelantan. The expansion of land use in 1845 until 1910 was dominantly for residential, while after year 1910, it was focused on commercial. The segregation of land use also shows that the state during the traditional era was focused more on the integration and social development with the location of the Palace, mosque and communal area close to each other and also the allocation for green area known as "Padang", and this finding is also consistent with the explanation of Harun \& Jalil (2014). Figure 6 shows the distribution of traditional Malay houses at the north/north west of study area and its integration with the surrounding land use. The Palace that located at the centre which became the node of the city and supported by the mosque where are only within 200 meters from the communal area.
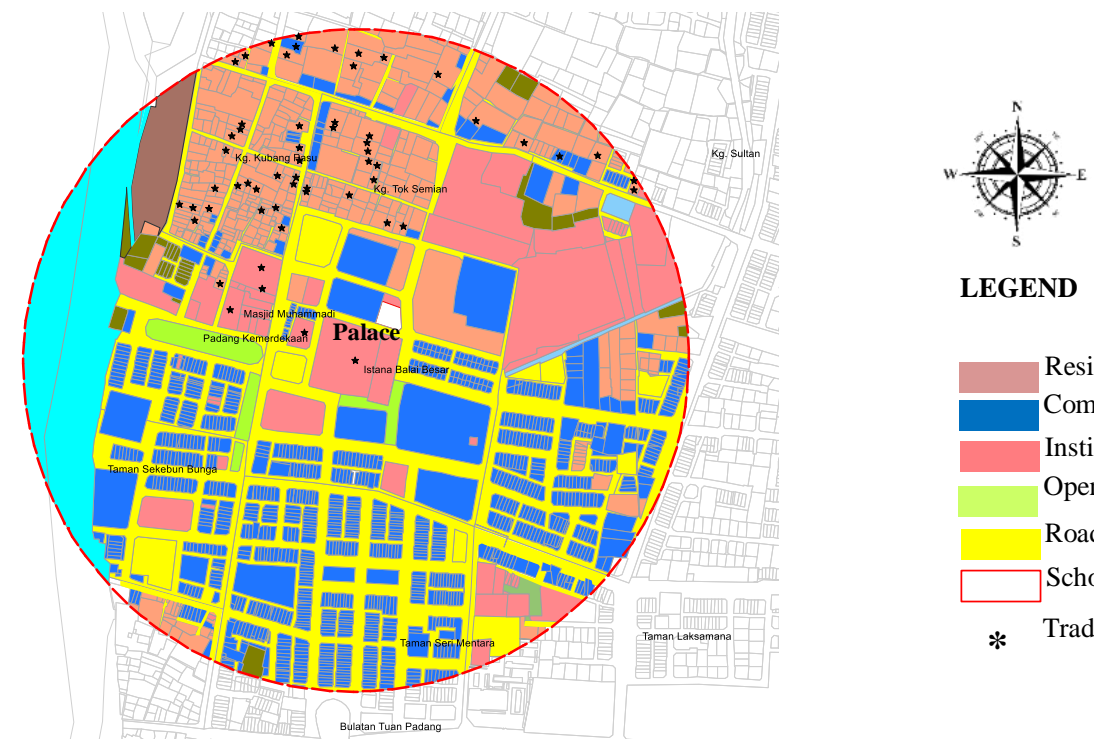

Figure 6: Categories of existing land uses and the asterisk (*) shows the distribution of Malay traditional houses in Kota Bharu

\section{CONCLUSION}

In this paper, we demonstrated 3D modeling reconstruction for the traditional Malay city of Kota Bharu using multirotor drone data and further analysis of the Malay urban form using GIS software. The potential of multirotor drones and 3D modelling were highlighted clearly. The drones can potentially be applied for the purpose of planning and conservation of heritage cities in Malaysia. These inexpensive drones are capable of making sophisticated maps that help a lot in decision making processes. Whereas $3 \mathrm{D}$ city models can be considered as one of the important and most helpful product in planning as visualization will improve 
Norzailawati Mohd Noor, Ahmad Afiq Aiman Abdullah, Alias Abdullah, Illyani Ibrahim \& Saadman Sabeek $3 D$ City Modeling Using Multirotor Drone for City Heritage Conservation

the efficiency in managing the planning process as well as it can be handy when dealing with decision makers, investors and communities. Based from the existing shape and form of city patterns, new development planning can be simulated using 3D city models to see the impact of a development. Geographical location, settlement formations and natural resources of early Malay towns and estuary towns in the Malay Peninsula have attracted outside influences which left significant impact on early urbanisation processes. The approach introduced in this study is expected to be the benchmark in shifting to technologies in conserving and safeguarding our heritage cities, specifically in Malaysia. Finally, for future researches, based on current challenges of this advanced world, more application of 3D city models with the integration of GIS should be developed or improved. Thus, it is recommended that for future studies, the 3D city model generated by UAVs/drones can be explored.

\section{ACKNOWLEDGEMENT}

Thanks to the International Islamic University of Malaysia and the Ministry of Higher Education (MOHE) for the research grant "Trans-Disciplinary Research Grant Scheme (TRGS16-03-002-00002)". Thanks also to Integrated GeoPlanning Sdn. Bhd. as our specialist support team who attended site visits. Authors would like to sincerely thank all referees for their suggestions to improve the manuscript.

\section{REFERENCES}

Clarke, R., (2014). Understanding the drone epidemic. Computer Law and Security Review, Vol. 30 (3), pp. 230-246

Li, D., Shan, J., Gong, J. (2009). Geospatial Technology for Earth Observation; Springer: New York, NY, USA, 2009; pp. 558.

Li, Z., Chen, J., Baltsavias, E., (2008). Advances in Photogrammetry, Remote Sensing and Spatial Information Sciences; ISPRS Congress Book 2008; Taylor \& Francis Group: London, UK, 2008; pp. 527.

Lin, A. Y. M., Novo A., Har-Noy S., Ricklin N.D., Stamatiou K., (2011). Combining GeoEye-1 Satellite Remote Sensing, UAV Aerial Imaging, and Geophysical Surveys in Anomaly Detection Applied to Archaeology, IEEE Journal of Selected Topics in Applied Earth Observation and Remote Sensing, 4(4), pp. $870-876$.

Greenwood, F., (2015). How to Make Maps with a Drones. Chapter 4 in Drones and Aerial Observation.

Harun, S. N., \& Jalil, R. A., (2014). The History and Characteristics of Malay Early Towns in Peninsular Malaysia, Vol. 2 (3), pp. $403-409$.

Hassanalian, M., \& Abdelkafi, A., (2017). Classification, Applications and Design Challenges of Drones: A Review. Progress in Aerospace Sciences, Vol. 91, pp. $99-131$. 
PLANNING MALAYSIA

Journal of the Malaysia Institute of Planners (2019)

Messoudi, T., Veron, P., Halin, G. \& Luca, L. D., (2018). An Ontological Model for the Reality-based 3D Annotation of Heritage Building Conservation State, Journal of Cultural Heritage, Vol. 29, pp. 100-112.

Zhang, L., Qiao, Z., Xing, W., Yang, L., Bao, Z., (2012). A Robust Motion Compensation Approach for UAV SAR Imagery., IEEE Transaction on Geoscience and Remote Sensing, 50 (8), pp. 3202-3218.

Received: $28^{\text {th }}$ October 2018. Accepted: $1^{\text {st }}$ March 2019 